\title{
Satellite monitoring of ice and snow conditions in the Sør Rondane Mountains, Antarctica
}

\author{
Frank Pattyn and Hugo Decleir \\ Geografisch Instituut, Vrije Universiteit Brussel, Pleinlaan 2, B-1050 Brussels, Belgium
}

\begin{abstract}
Six multispectral SPOT images and one Landsat Thematic Mapper image of the central part of the Sør Rondane Mountains, Dronning Maud Land, Antarctica, were obtained over a five year period (1986-90) and studied for their potential in mapping the glacierized surface. From the thermal IR reflectances of Landsat TM a map of ice and snow temperatures was obtained, reflecting largescale topography. The "middle" IR and "near" IR bands (in descending order of importance) enhance markedly the variations on the snow surface itself. This can be most clearly seen in the accumulation area north and south of the range where the snow cover is abundant.

From multispectral SPOT imagery a glacio-morphological map was created. Some aspects of this map are discussed with respect to the significance of the ablation in this isolated mountain area, where the main ice stream is diverted around the range. Finally, an analysis of multitemporal images led to the development of a classification tool to quantify the extent of ablation and accumulation areas. Also, by this method drift snow could be distinguished from the permanent snow cover.
\end{abstract}

\section{INTRODUCTION}

Despite all efforts, Antarctica still remains a remote place of which little is known. Most of the scientific measurements are restricted to isolated spots, generally close to the coast. Nevertheless, there is a need for a generalisation of this knowledge to other places on this huge continent, i.e. for the construction and updating of global Antarctic data bases related to topography, temperature and mass balance. The extrapolation and quantification over much larger areas is now becoming possible by the exploitation of data from remote sensing platforms, such as earth resource satellites.

This study presents the results of a detailed analysis of Landsat Thematic Mapper and multidate/multispectral SPOT imagery for their use in glaciological and glaciocartographic studies in the Sør Rondane Mountains, a typical coastal mountain range in Dronning Maud Land, East Antarctica. The field evidence was collected through participation in the Japanese Antarctic Research Expeditions JARE 28 (1986-87), JARE 31 (1989-90) and JARE 32 (1990-91).

\section{REGION DESCRIPTION AND REMOTE SENSING DATA ACQUISITION}

The Sør Rondane Mountains $\left(20-30^{\circ} \mathrm{E}, 71-73^{\circ} \mathrm{S}\right)$ are a $220 \mathrm{~km}$ long mountain range, oriented east-west, situated $200 \mathrm{~km}$ from the coast. Up to now, the central part has been extensively studied. A detailed glacio-geomorphological description of the range is given in Van Autenboer
(1964). Recent glaciological evidence on the glacierization process and basal topography of the mountain range can be found in Pattyn and others (unpublished).

Six multispectral SPOT images and one Landsat Thematic Mapper (TM) image of the central part of the Sør Rondane were obtained over a five year period (1986-90). Figure 1 shows the geographical distribution of those images. The TM image (ID 5100706072), recorded on 3 December 1986, incorporates seven spectral bands, which will be further referred to as TM1..TM7. SPOT multispectral imagery include only three spectral bands (referred to as XS1..XS3). The six SPOT images are 153-688 and 153-690, recorded on 8 February 1987, 152-689, recorded on 15 February 1987, 149-689, recorded on 20 February 1990, and 151-688 and 151-690, both recorded on 21 February 1990. The wavelength regions of the different spectral bands for both platforms are given in Figure 2.

\section{SPECTRAL INFORMATION CONTENT OF LAND- SAT TM AND SPOT IMAGERY}

Choudhury and Chang (1981) investigated solar reflectance of snow for different grain sizes. They found that generally the snow albedo (reflectance) decreases with increasing grain size. This explains why snow can be differentiated from bare ice and even fresh snow from older compacted snow. The variation in reflectance with grain size is, however, small in the visible wavelengths (TM1, TM2, TM3, XS1, XS2) but increases considerably above about $0.7 \mu \mathrm{m}$. The infrared reflective bands 


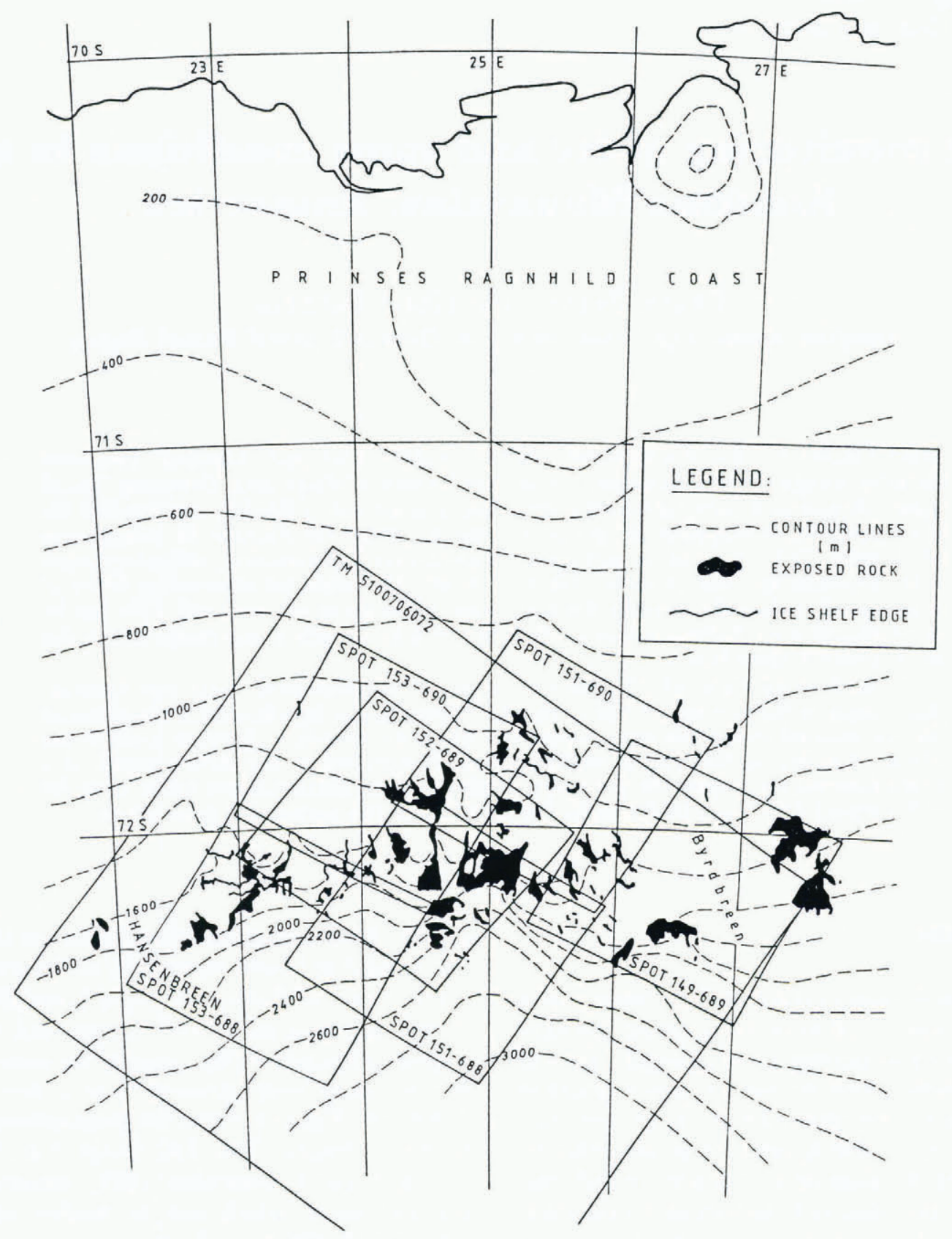

Fig. 1. Index map showing location of Landsat TM and SPOT images discussed in this paper.

(TM4, TM5, TM7, XS3) are, therefore, very appropriate for distinguishing different snow and ice structures. Also, the reflectance decreases drastically with increasing wavelength, becoming almost zero in TM5 and TM7. At those wavelengths the images show that snow is even more absorptive than rock.

From the "pure" visible wavelengths (TM1, TM2, TM3, XS1, XS2) only TM2, XS1 and XS2 discriminate ice from snow, whereas TMl and (partly) TM3 are saturated on snow and ice. Nevertheless, shadows that become large due to the low sun angle and steep relief of the rock outcrops are highly transparent in TM1, so that the boundary between rock and glacier in shadowed areas can be determined. TM4 and XS3 ("near" infrared) provide much greater information for snow and ice, both because TM4 lacks saturation (due to the lower

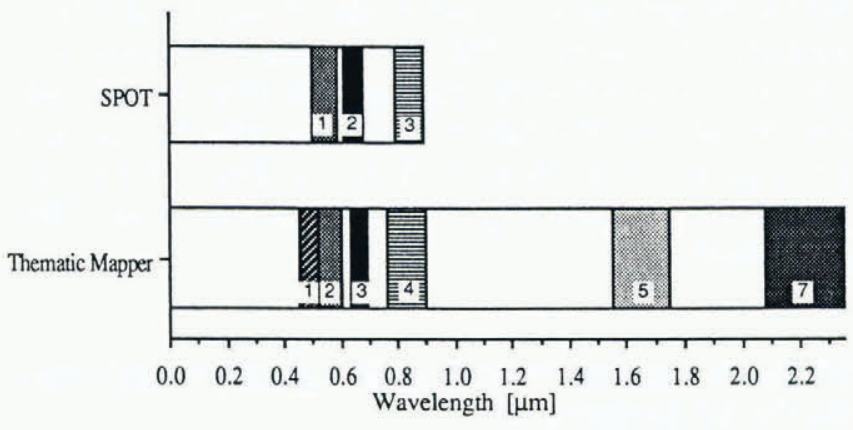

Fig. 2. Wavelength regions and band width of Landsat $T M$ (except thermal IR band) and SPOT scanner systems. 
reflectance of snow), and because it shows good contrast in snow and ice. Especially large-scale snow and ice features such as crevassing, flow lines, lateral and longitudinal undulations are enhanced by photometric shading caused by the low sun angle prevalent over Antarctica (Orheim and Lucchitta, 1987). In TM5 and TM7, surface features, earlier described as blue ice zones or vast snow areas, show different patterns in their reflectance signature, primarily due to variations in grain size or to other surface properties of snow and ice.

From multitemporal SPOT images it was found that the reflectances of certain snow areas differed greatly in time, sometimes leading to an excessive saturation of the satellite detectors, especially at shorter wavelengths. This is probably due to a change in illumination angles (when images are recorded several weeks apart) and the different atmospheric conditions, hampering the analysis of multitemporal data.

\section{SURFACE TEMPERATURES IN THE CENTRAL SØR RONDANE}

Landsat TM band 6 (TM6) provides radiometric surface temperatures and, in particular, it shows a strong signal for "warm" parts within the region of snow and ice (Orheim and Lucchitta, 1988). Radiation at terrestrial temperatures is strongest between $9 \mu \mathrm{m}$ and $14 \mu \mathrm{m}$, with a maximum around $11 \mu \mathrm{m}$ at temperatures in the range $-25^{\circ} \mathrm{C}$ to $0^{\circ} \mathrm{C}$. This maximum is covered by TM6 (10.40$12.50 \mu \mathrm{m})$ and lies also in the atmospheric window with reduced atmospheric absorption, so that this band effectively records relative ground temperatures.

The scene-dependent values of the minimum $\left(L_{\min }\right)$ and maximum $\left(L_{\max }\right)$ spectral radiances from the two calibration sources onboard the satellite (Landsat-5) are read from the Header File, supplied with the image on the Computer Compatible Tapes, and are related to the spectral radiance of the scene as follows:

$$
L \lambda=\left(L_{\max }-L_{\min }\right) \frac{D N}{255}+L_{\min }
$$

with $L \lambda$ the spectral radiance $\left[\mathrm{mW} \mathrm{cm}^{-2} \mathrm{sr}^{-1} \mu \mathrm{m}^{-1}\right], D N$ the digital number ranging from 0 to 255 and $L_{\min }$ and $L_{\max } 0.12378$ and $1.55996 \mathrm{~mW} \mathrm{~cm}^{-2} \mathrm{sr}^{-1} \mu \mathrm{m}^{-1}$, respectively. Singh (1988) proposes an accurate algorithm for converting TM6 digital numbers into brightness temperatures. The relation between the spectral radiance $L \lambda$ and temperature $T$ is then given as:

$$
T=\frac{b}{\ln (L \lambda)-a}
$$

with $T$ the brightness temperature $(\mathrm{K})$. Values for $a$ and $b$ are determined for temperature ranges of $40 \mathrm{~K}$ only, which enhances the accuracy. For a spectral radiance between 0.19968 and $0.48350(220 \leq T \leq 260)$, values of $a$ and $b$ are 4.1368 and -1264.63 , respectively. At higher spectral radiances (between 0.48350 and 0.92949 ), values of $a$ and $b$ equal 4.1754 and -1274.674 , respectively (Singh, 1988).

The algorithm is then applied to the central part of the Sør Rondane, resulting in a map of surface brightness temperatures (Fig. 3). The situation of this map within
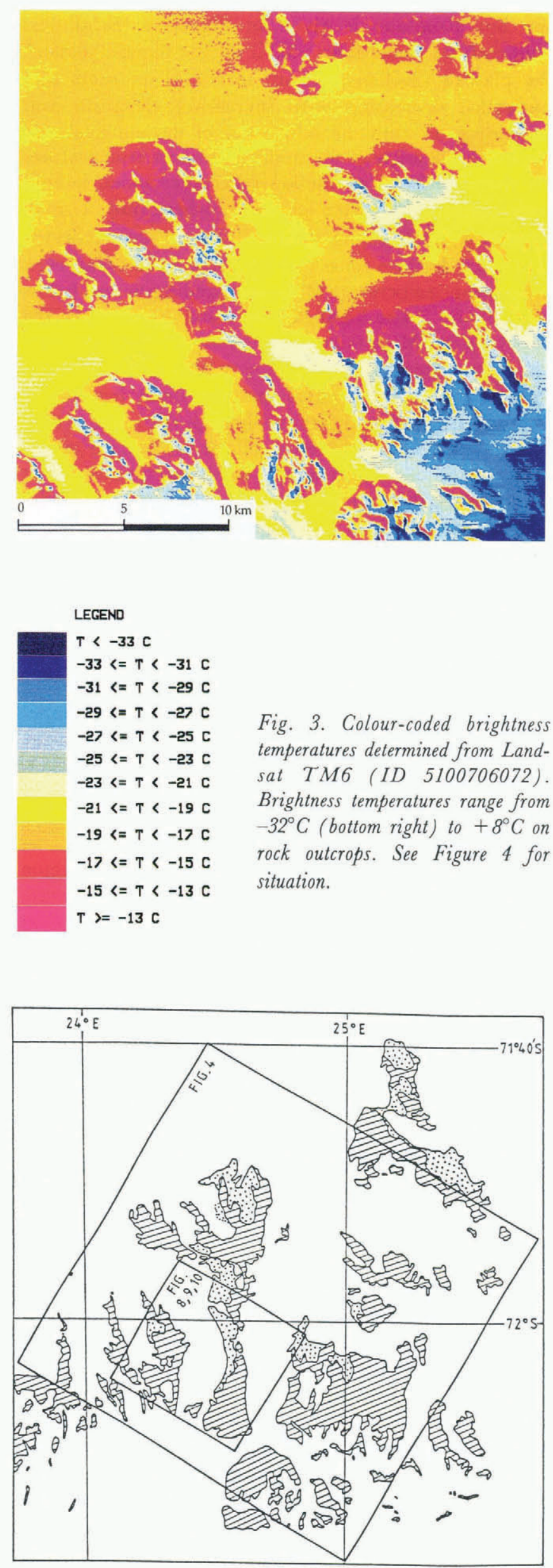

Fig. 4. Situation sketch for the displayed Landsat TM (Fig. 3) and SPOT images (Figs 8, 9 and 10). 
the Sør Rondane is given in Figure 4. Brightness temperatures range from $-32^{\circ} \mathrm{C}$ on the highest parts of the plateau ( $2600 \mathrm{ma}$ a.s.l.) up to $+8^{\circ} \mathrm{C}$ on rocks and nunataks, decreasing with increasing elevation and depending on both the reflectivity of the material and the incidence angle of the sun. The highest temperatures are therefore found on the low reflectance zones, such as rock outcrops and bare ice zones, where only a small amount of the incoming radiance from the sun is reflected into space. In these zones melting phenomena occur, even if the mean temperature of the surroundings is well below zero. Figure 3 also highlights the damming effect of the Sor Rondane Mountains upon the main ice stream from the polar plateau: it shows the very high and hence cold surfaces south of the range and the rapid increase in temperature as the glaciers cut through the range, which is associated with a lowering of the ice surface and a change from snow cover to bare ice due to the oasis effect (i.e. increase in temperatures caused by the low albedo, adiabatic heating and wind shelter from the surrounding nunataks).

To calculate real surface temperatures one should retain only thermal radiances of one texture unit, defined by a constant albedo. Since the snow coverage is most abundant in the image, only brightness temperatures on the snow surface were extracted. This was done by an overlay operation between a classified Thematic Mapper image, displaying snow and ice cover and the TM6 image of the same region. For 68 pixels on the snow surface, terrain heights were extracted from a topographic map, so that a relation could be established between the surface topography and brightness temperature (Fig. 5).

A simple linear regression analysis for the region between 900 and $2600 \mathrm{~m}$ shows a mean temperature gradient of $-8.5^{\circ} \mathrm{C} / \mathrm{km}$, with a temperature of $-7.8^{\circ} \mathrm{C}$ at sea level. Two field parties of JARE 28 measured air temperatures in the Sør Rondane region between 21 November and 6 December 1986. The first field station was situated at Asuka $\left(71^{\circ} 32^{\prime} \mathrm{S}, 24^{\circ} 08^{\prime} \mathrm{E}, 965 \mathrm{~m}\right.$ a.s.l.), $60 \mathrm{~km}$ north of the central Sør Rondane, while the second (SS100) was situated on the polar plateau $\left(73^{\circ} 07^{\prime} \mathrm{S}\right.$, $39^{\circ} 45^{\prime} \mathrm{E}, 3005 \mathrm{~m}$ a.s.l.), $520 \mathrm{~km}$ southeast of our study area. Air temperatures were measured at least twice a day ( $0600 \mathrm{~h}$ and $1800 \mathrm{~h} \mathrm{GMT}$ ) at $2 \mathrm{~m}$ above the snow surface with an alcohol thermometer (Nishio and others, 1988). A rather constant temperature trend was observed over the period 27 November to 6 December 1986. The Landsat TM image was recorded on 3 December 1986 at $0607 \mathrm{~h}$ GMT. Temperatures at Asuka and SS100 then amounted to $-8.5^{\circ}$ and $-25.0^{\circ} \mathrm{C}$, respectively. Relating these temperatures linearly to elevation, one obtains a temperature gradient of $-8.1^{\circ} \mathrm{C} / \mathrm{km}$, which is in accord with the TM6 brightness temperature gradient of $-8.5^{\circ} \mathrm{C} /$ $\mathrm{km}$. However, the absolute temperatures recorded at both stations lie approximately $9^{\circ} \mathrm{C}$ lower than the brightness temperatures, probably due to the fact that brightness temperatures cannot be confused with air temperatures. Strong winds at the time of image acquisition $\left(12.0 \mathrm{~m} \mathrm{~s}^{-1}\right.$ at Asuka) imply an efficient heat exchange between the snow surface and the air, so that surface temperatures might lie within the realm of the air temperatures ( $T$. Vinje in Orheim and Lucchitta, 1988).

Surface temperatures should not differ very much

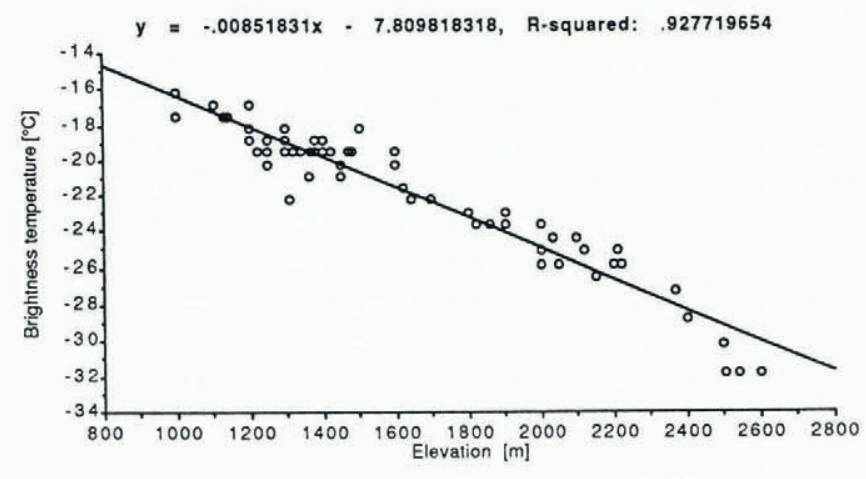

Fig. 5. Regression analysis applied to Landsat TM6 data. Brightness temperatures were chosen on snow and plotted as a function of surface elevation $(n=68)$.

from the brightness temperatures for the following reasons: (i) brightness temperatures depend on the emissivity of the surface, but snow emissivity deviates little from unity (longwave emissivity of snow is typically 0.99 and 0.97 for bare ice surfaces), and (ii) TM6 is not sensitive to changes in the properties of the snow surface, as is the case with the "middle" infrared bands TM5 and TM7. Orheim and Lucchitta (1988) also found a similar discrepancy between measured temperatures and brightness temperatures. Their difference in temperature offset varied between $8^{\circ}$ and $20^{\circ} \mathrm{C}$. In practice, the interpretation of thermal data and images of areal temperature distribution over snow is far from simple, as the measured radiance depends on the emissivity of the surface (which is also a function of viewing angle), the wavelength region, and also on atmospheric effects. Massom (1991) mentions that the contribution of atmospheric effects might be great in polar regions.

A recent parameterisation of the annual surface temperature over Antarctica (Fortuin and Oerlemans, 1990) also agrees with the TM6 results. For the Antarctic continent, a mean lapse rate of $-9.14^{\circ} \mathrm{C}\left( \pm 0.343^{\circ}\right)$ was obtained. A separate temperature gradient was calculated by these authors for the inland ice slope (200$1500 \mathrm{ma}$ a.s.l.) and the interior (above $1500 \mathrm{~m}$ a.s.l.). Lapse rates of -5.1 and $-14.3^{\circ} \mathrm{C} \mathrm{km}^{-1}$, respectively, were found. In our area, a linear regression analysis on the TM6 data reveals temperature gradients of -6.4 and $-10.3^{\circ} \mathrm{C} \mathrm{km}^{-1}$ for the elevation zone $900-1500 \mathrm{~m}$ and $1500-2600 \mathrm{~m}$, respectively.

We can conclude that the TM6 thermal infrared band effectively records relative ground temperatures. Nevertheless, a large offset $\left(9^{\circ} \mathrm{C}\right)$ exists between the measured surface temperatures and the TM6 brightness temperatures, probably attributed to atmospheric conditions and illumination angle. In the Sør Rondane, different temperature gradients are observed for the inland ice slope ( $<1500 \mathrm{~m}$ a.s.l.) and the polar plateau, in accord with parameterizations of the surface temperature over Antarctica.

\section{SPOT IMAGERY AND GLACIER MAPPING}

One main advantage of the European SPOT satellite 


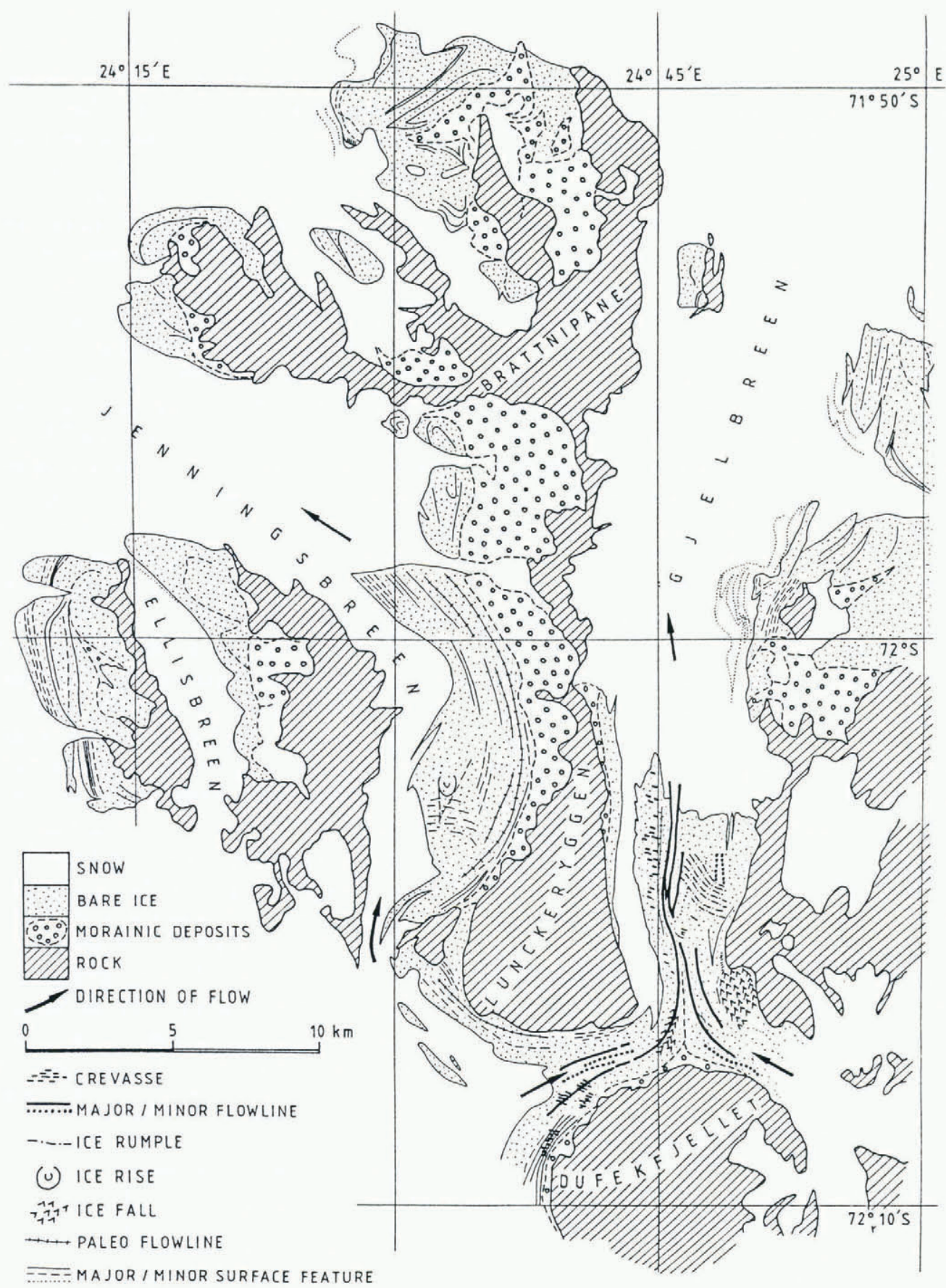

Fig. 6. Glacio-morphological map of the glaciers as the central part of the Sor Rondane Mountains, based on an interpretation of multispectral SPOT images.

compared to the Landsat-5 Thematic Mapper is the larger pixel resolution $(20 \mathrm{~m}$ in multispectral mode and $10 \mathrm{~m}$ in panchromatic mode). However, SPOT lacks the infrared reflective and infrared emissive (thermal) bands so that it is not possible to extract detailed information concerning the physical properties of the snow surface, nor surface temperatures. Despite this shortcoming, SPOT multispectral images of Antarctica reveal much information on the glacierized surface and bare ice areas situated at the lee side of nunataks in the central Sør Rondane. The reflectances on the bare ice reveal details not visible on aerial photographs nor in multispectral compositions of Landsat TM images. On the basis of a visual interpretation of a colour composite combining SPOT multispectral channels XS1, XS2 and XS3, a glaciological map of the central part of the Sør Rondane was created (Fig. 6), displaying the surface characteristics of the glaciers Jenningsbreen and Gjelbreen.

Two different types of surface features could be identified in the SPOT image, i.e. topographic and spectral. Topographic features are a result of strain rates in the glacier (obstruction of flow, side drag from the glacier walls) or an effect of the wind. Both actions result in height changes on the surface. Such topographic 
features are found on Gjelbreen, the only real active glacier in this part of the range (Van Autenboer and Decleir, 1978; Pattyn and others, unpublished). Extensive flowlines and ice rumples on this glacier are due to strain rates which are mainly caused by the confluence of two ice streams. At the entrance of Jenningsbreen and Gjelbreen in the mountain range, two distinctive ice falls reflect the abrupt change in basal topography. Also, heavy crevassing in the south and large crevasses further downstream underscore the glacial activity.

Spectral features on the other hand are not reflected at the surface by a relief disturbance, but are characterised by differences in spectral response measured by the satellite. Most of these patterns are found on the bare ice areas of the "local" glaciers such as Jenningsbreen, and at the lee side of nunataks and rock parts of the mountain range. By local glaciers we mean outlet glaciers with considerable ice thickness, but which have been (or are) in the process of being cut off from the main ice supply (Pattyn and others, unpublished). This is due to a lowering of the ice sheet surface behind the mountains. Ablation dominates on these glaciers and they have become nearly stagnant with extensive supraglacial moraines at their margins. The conspicuous textural lines on Jenningsbreen, suggesting flowlines, can therefore be interpreted as paleo-flowlines. Also, a peculiar kind of banding in the ice is detected, especially at the extensive bare ice field north of Brattnipane. This ice field is characterised by a steep slope, so that these bands might be interpreted as an outcropping of different subhorizontal ice layers.

During JARE 31 only a few of these bands were observed in the field. The appearance of these zones is darker as they contain fewer air bubbles than the blue ice. The few ice bubbles are nonetheless bigger in size. Lliboutry (1964) describes different sorts of ice depending on their amount in air bubbles: white ice contains many air bubbles and is in most cases formed by firnification at the ice surface. Blue ice contains fewer air bubbles, while superimposed ice is formed by refreezing at the surface and is poor in air bubbles. Thus, the more bubbles captured in the ice, the higher the albedo. The occurrence and formation of "darker lines" in the bare ice zones probably point to foliation or stratification of ice, implying a layered structure of sedimentary ice produced by the superimposition of younger layers over older layers of ice (Lliboutry, 1964; Kotlyakov and Smolyarova, 1990).

\section{GHANGE DETECTION WITH MULTITEMPORAL SPOT IMAGERY}

Orheim and Lucchitta (1990) have already referred to the importance of change detection in the extent of bare ice areas in view of climate change. Bare ice areas are ablation areas and thus have a negative mass balance. They indicate an emergence of old ice at the surface which is caused by several processes. Bare ice areas occur on places where the accumulation is reduced due to wind scouring and reduced snowdrift at the lee sides of nunataks (wind sheltered zones). Once they are established they survive by increased ablation, due to the low surface albedo, long-wave radiation of the nearby rocks, high temperatures caused by adiabatic heating, and wind erosion. Near the nunataks themselves, surface melting occurs during the day, so that repeated melting and refreezing give rise to the formation of smooth surfaces. During JARE 32, some lakes were observed on the ice surface of Jenningsbreen, reaching depths of 5-10 cm.

To determine the rate of change in the extent of bare ice areas, a selective principle component analysis was applied on the 1987 (153-690) and 1990 (151-688) SPOT images as proposed by Orheim and Lucchitta (1990), after performing a precise matching of these images in the same reference frame. The results showed a spectacular decrease in bare ice extent in the central Sør Rondane from $53 \%$ of the total glacierized surface in 1987 to $19 \%$ in 1990. However, a field party of JARE 31 (1989-90) observed a severe snowstorm at the beginning of January 1990, lasting one week, which covered the whole glacier surface of Jenningsbreen in snow for more than a month. In 1991 the ice extent was back to normal. This change in extent obviously points to a weather phenomenon rather than to climate change.

To detect changes at the bare ice surface related to climate change, a supervised classification technique was used to distinguish permanent snow cover from ice surfaces buried underneath a layer of snowdrift. In addition, such a classification is the only technique by which the image information can be quantified: by assigning each pixel to a particular class it becomes possible to calculate the areal extent of the snow and ice cover. Three classes on the glacierized surface were retained, i.e. snow, bare ice and ice covered with a layer of snowdrift (referred to as ice/snow). For each of these classes, several training areas (groups of pixels of which texture is known from field evidence) were chosen, dispersed over the image. A preliminary study of classification techniques revealed that the decision-tree classifier (Mather, 1989) was the most suited, both

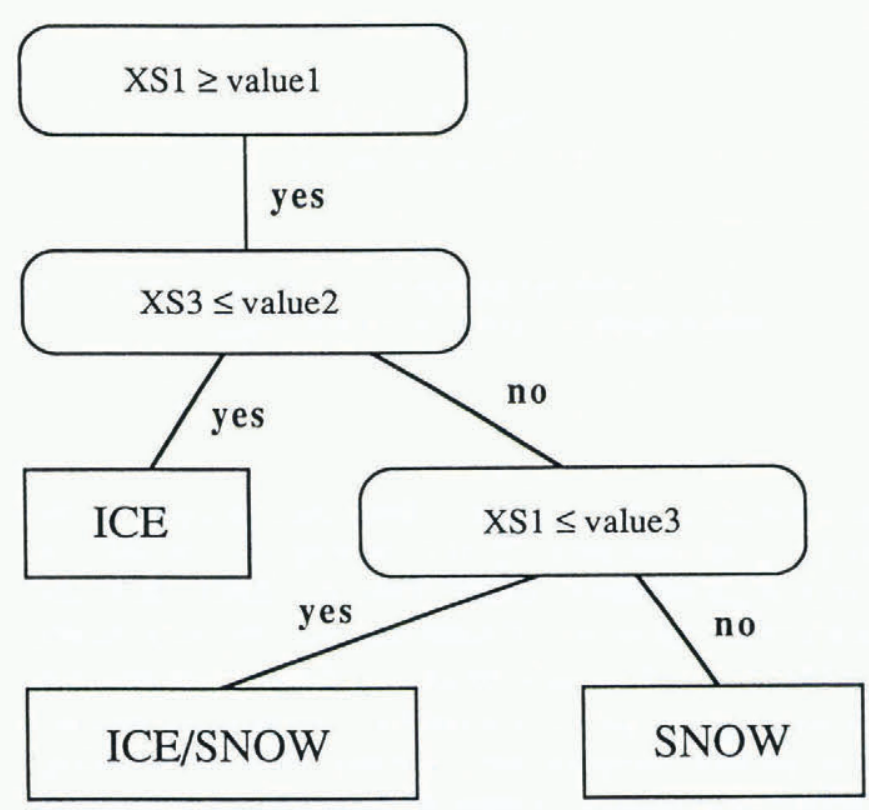

Fig. 7. Decision tree of the classification process with SPOT imagery. Discrimination values are reported in Table 1. 
because of a good overall classification accuracy as well as the simplicity of the method. A decision tree (Fig. 7) was created after careful inspection of the training class statistical parameters, such as mean class grey value and

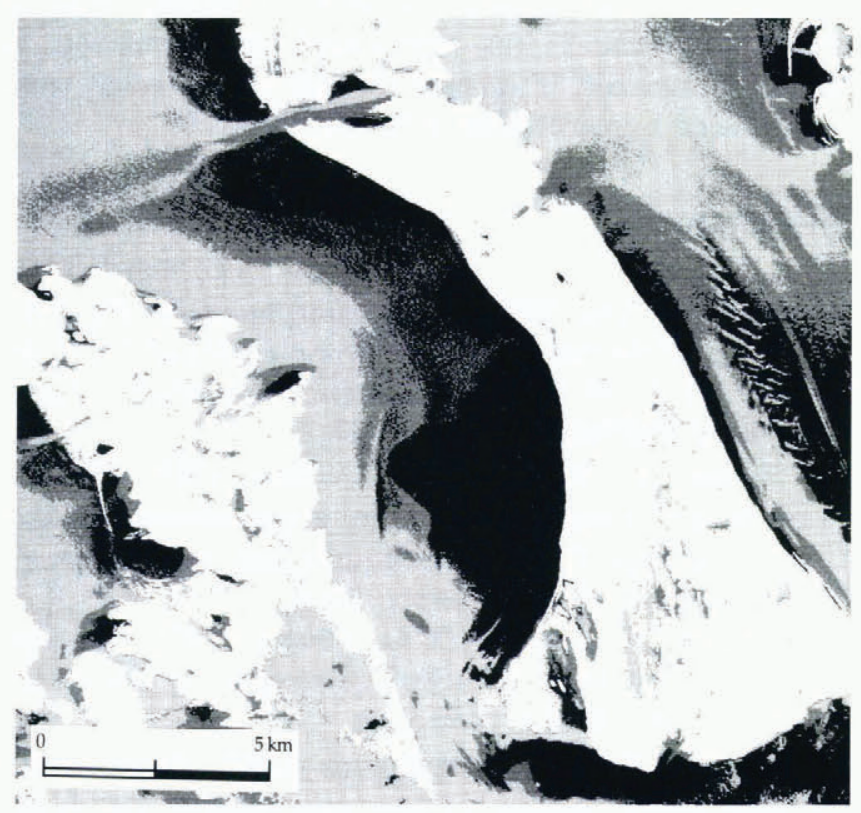

Fig. 8. Classification of SPOT scene 153-690 (8 February 1987) according to the decision tree classifier of Figure 6. Rock outcrops and morainic debris are displayed in white, bare glacier ice in black, ice covered with a layer of snowdrift (snow/ice) in grey and snow in light grey. See Figure 4 for situation.

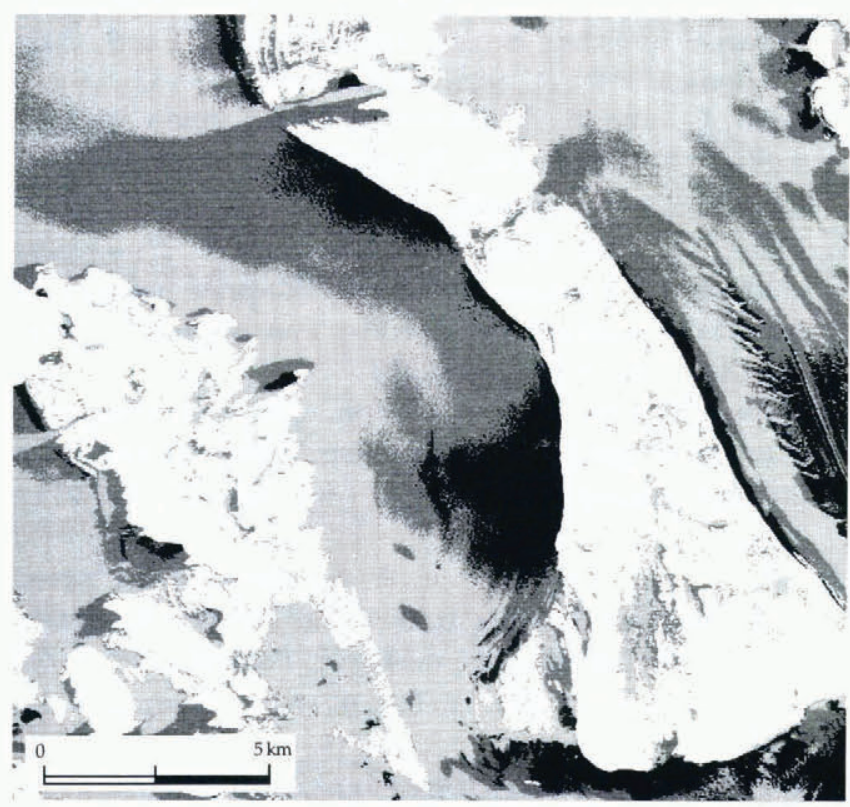

Fig. 9. Classification of SPOT scene 151-688 (21 February 1990) according to the decision tree classifier of Figure 6. Rock outcrops and morainic debris are displayed in white, bare glacier ice in black, ice covered with a layer of snowdrift (snow/ice) in grey and snow in light grey. See Figure 4 for situation.
Table 1. Discrimination grey values (Digital Number) of the decision tree classifier for the 1987 and 1990 SPOT images

Value $1 \quad$ Value $2 \quad$ Value 3

$\begin{array}{llll}1987 & 140 & 72 & 178 \\ 1990 & 140 & 62 & 179\end{array}$

Table 2. Areal extent (\% of total surface) of the different texture classes for the 1987 and 1990 SPO T images (Figs 7 and 8)

1987

1990

$\%$

$\%$

Rock, morain cover, shadow

34.66

34.11 Ice

19.77

9.30

Ice/snow

16.10

24.00

Snow

29.46

32.60

Total ablation area

35.87

33.30 standard deviation. With this method each pixel in the image is uniquely assigned to a particular class. The discrimination values for the 1987 and 1990 images are given in Table 1 (see also Fig. 7).

Figures 8 and 9 are the classified images of 1987 and 1990, respectively, displaying rock and morainic debris (white), bare glacier ice (black), ice/snow (grey) and snow (light grey). Table 2 gives the surface extent of all classes of the two images. A considerable decrease in bare ice can be observed, but taking into account the ice/snow class, the total ablation area decreased with only $2-3 \%$ of the total area. A simple arithmetic operation on Figures 8 and 9 then visualizes the changes at the glacier surface (Fig. 10). The blue colour represents a change from ice (dark blue) or ice/snow (light blue) into snow, red a change from snow to ice/snow (light red) or ice (red), while yellow points to changes from ice to ice/snow and vice versa. In terms of ablation/accumulation, blue might be interpreted as a change from ablation into accumulation, red as a change from accumulation into ablation, while the most abundant colour (yellow) implies no real change at all. Although we noted only a minimal change in total ablation surface extent (Table 2), Figure 10 shows a significant displacement in accumulation and ablation areas: we observe an increase in ablation on the central part of the glaciers (red) and an increase in accumulation in the wind-protected zones (blue). This might indicate a reduced oasis effect in the wind-sheltered areas and an increased wind effect elsewhere. 


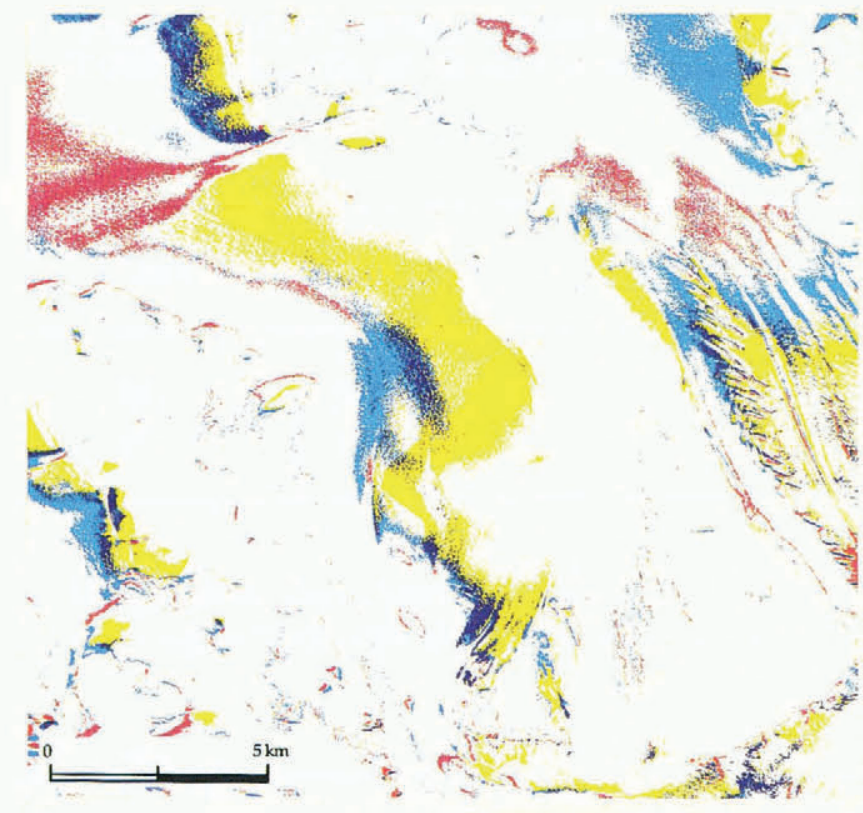

Fig. 10. Overlay operation on Figures 7 and 8, displaying variations in ice and snow conditions in the central Sor Rondane over a period of three years. The blue colour represents a change from ice (dark blue) or ice/snow (light blue) into snow, red a change from snow to ice/snow (light red) or ice (red), yellow points to changes from ice to icel snow and vice versa, and white means no change.

\section{CONGLUSIONS}

The use of satellite images in polar regions facilitates the interpretation of ground data and extrapolation of fragmentary field knowledge to much larger coherent areas. Applied to the central part of the Sør Rondane, Landsat TM imagery is shown to be very useful in the detection of differences in properties of the abundant snow cover and the extraction of snow surface temperatures. Topographic mapping of glacier surfaces with SPOT resulted in a glacio-morphological map of the glaciers of the central Sør Rondane displaying morphological features on the glacier surface. Finally, in vew of the possibility of climatic change, a classification technique allowed the determination of the extent of accumulation and ablation zones of the glacierized surface. A combination of multitemporal classified images resulted in a map displaying temporal changes in bare ice extent.

\section{ACKNOWLEDGEMENTS}

The research presented in this paper was performed under contract ANTAR/II/04 (Belgian Scientific Research programme on Antarctica) and under contract TELSAT/II/05 (Belgian Scientific Research Programme on Remote Sensing by Satellite) of the Belgian Science
Policy Office. The authors are deeply indebted to Professor T. Hoshai, Director of the National Institute of Polar Research (Japan), for the generous support of our programme. During JARE 32 (1990-91) we enjoyed the field company and invaluable assistance of $\mathrm{K}$. Shiraishi and S. Iwata. Landsat Thematic Mapper Scene 5100706072 was reproduced by permission of EOSAT, and SPOT images 153-690 and 151-688 were reproduced by permission of SPOT IMAGE.

\section{REFERENCES}

Autenboer, T. van. 1964. The geomorphology and glacial geology of the Sør-Rondane, Dronning Maud Land. In Adie, R.J., ed. Antarctic geology. Amsterdam, North Holland Publishing Co., 81-103.

Autenboer, T. van and H. Decleir. 1978. Glacier discharge in the Sør-Rondane, a contribution to the mass balance of Dronning Maud Land, Antarctica. Z. Gletscherkd. Glazialgeol., 14(1), 1-16.

Choudhury, B.J. and A. T.C. Chang. 1981. On the angular variation of solar reflectance of snow. $\mathcal{J}$. Geophys. Res., 86(C1), 465-472.

Fortuin, J. P. F. and J. Oerlemans. 1990. Parameterization of the annual surface temperature and mass balance of Antarctica. Ann. Glaciol., 14, 78-84.

Kotlyakov, V. M. and N.A. Smolyarova, comps. 1990. Elsevier's dictionary of glaciology in four languages. Amsterdam, Elsevier.

Lliboutry, L. 1964. Traité de glaciologie. Tome 1. Paris, Masson.

Massom, R. A. 1991. Satellite remote sensing of polar regions. London, Belhaven; Boca Raton, FL, Lewis Publishers.

Mather, P. M. 1989. Computer processing of remotely-sensed images. Chichester, etc., John Wiley and Sons.

Nishio, F., H. Ohmae and K. Osada. 1988. Glaciological research program in east Queen Maud Land, East Antarctica. Part 7, 1986. JARE Data Rep. 137.

Orheim, O. and B. K. Lucchitta. 1987. Snow and ice studies by Thematic Mapper and multispectral scanner Landsat images. Ann. Glaciol., 9, 109-118.

Orheim, O. and B.K. Lucchitta. 1988. Numerical analysis of Landsat Thematic Mapper images of Antarctica: surface temperatures and physical properties. Ann. Glaciol., 11, 109-120.

Orheim, O. and B. K. Lucchitta. 1990. Investigating climate change by digital analysis of blue ice extent on satellite images of Antarctica. Ann. Glaciol., 14, 211215.

Pattyn, F., H. Decleir and P. Huybrechts. In press. Glacierization of the central part of the Sør-Rondane, Antarctica: glaciological evidence. Proceedings of the 6th International Symposium on Antarctic Earth Sciences, Tokyo 1991.

Singh, S. M. 1988. Brightness temperature algorithm for Landsat Thematic Mapper data. Remote Sensing Environ., 24, 509-512.

The accuracy of references in the text and in this list is the responsibility of the authors, to whom queries should be addressed. 